\title{
Exploring the interdependence of couples' rest-wake cycles: an actigraphic
}

\section{study}

\author{
Robert Meadows ${ }^{1}$, Sara Arber ${ }^{1}$, Susan Venn ${ }^{1}$, Jenny Hislop ${ }^{2}$ and Neil Stanley ${ }^{3}$ \\ ${ }^{1}$ Department of Sociology, University of Surrey, Guildford, Surrey GU2 7XH, UK \\ ${ }^{2}$ Institute of Life Course Studies, Keele University, Keele, Staffs ST5 5BG, UK \\ ${ }^{3}$ Clinical Research and Trials Unit, Norfolk and Norwich University Hospital, UK
}

This study was funded by UK Economic and Social Research Council grant RES-000-230268 .

\section{Correspondence to:}

Robert Meadows

Centre for Research on Ageing and Gender

Department of Sociology

School of Human Sciences

University of Surrey

Guildford

Surrey

Tel: 01483689292

Fax: 01483689090

Email: r.meadows@ surrey.ac.uk 


\begin{abstract}
Within western societies it is commonplace for couples to share a bed. Yet there has been remarkably little research carried out on couples' sleep. This paper draws upon actigraphy, audio diary and questionnaire data from both partners in 36 heterosexual couples (age 20-59) and aims to quantify the extent to which it is important to take the dyadic nature of sleepwake cycles into account. It achieves this through two interrelated aims: (i) to use Hierarchical Linear Models to measure dyadic interdependence in actigraphically recorded variables; and (ii) to investigate how much of this dyadic interdependence truly results from couple dynamics. The variables with the most significant couple interdependency were 'Actual bed time', 'Sleep latency', 'Light/Dark ratio' and 'Wake bouts'. The paper concludes by suggesting that interdependence may be the defining feature of couples' sleep and that we need to employ analytic approaches which both acknowledge this and which are sensitive to the possibilities that not all aspects of sleep will behave in the same way.
\end{abstract}

Key words: couples, sleep, actigraphy 


\section{Introduction}

A paradox exists within sleep research. On the one hand, it has long been recognised that 'the common practice of sharing a bed might be a significant contributing factor to daytime sleepiness and chronic sleep loss' (Kushida 2004, p. 133). Nearly forty years ago Monroe (1969) highlighted how sleep architecture improves when bed partners sleep alone. In his study of 14 couples, Monroe found that lone sleeping significantly increased the amount of stage 4 sleep and reduced the number of awakenings by 60 per cent.

Yet, despite the existence of a nascent literature on couples' sleep quality (Cartwright and Knight 1987; Pankhurst and Horne 1994; Beninati et al 1999; Ulfberg et al 2000; Parish and Lyng 2003; Strawbridge et al 2004; Rosenblatt 2006; Dittami et al 2007; Venn 2007), discussions of couples' sleep-wake remain largely confined to review articles (Troxel et al 2007), 'brainstorms' (Adams and Cromwell 1978, p. 11) or studies of marital quality (Larson et al 1991). It is still the case that 'almost everything that has been published in the social and behavioural sciences and in medicine about adult sleep has looked at adult sleep as an individual phenomenon' (Rosenblatt 2006, p. 1), with studies largely ignoring the potential dyadic nature of bed partner's sleep.

Given this contradiction, this paper aims to quantify the extent to which it is important to take the dyadic nature of sleep-wake cycles into account. It achieves this through two interrelated aims: (i) to measure dyadic interdependence in actigraphically recorded variables; and (ii) to investigate how much of this dyadic interdependence truly results from couple dynamics.

\section{Methods}

Forty heterosexual couples were recruited in South East England in 2004-2005. Flyers were hand delivered around housing estates in the South East of England (eliciting an average response of 1 couple per 100 flyers). Participants were also invited to pass on details of the study to family and friends. Each participating couple received $£ 100$ to compensate them for their time and commitment.

Inclusion criteria were that the male in the couple was aged between 20 and 59 inclusive and must be married or cohabiting. Female subjects could also not knowingly be pregnant at the beginning of the project. All participants continued their normal sleep/wake routine throughout a one week data collection period and no restrictions were placed on activities, 
food or drink. The study was approved by the University of Surrey ethics committee and conformed to international ethical standards (Touitou et al 2006).

Due to non-compliance or missing data the analysis set included 36 couples. The age range for the men was 21 years to 59 years $($ mean= 39.83; sem=1.92). The women ranged from 22 years to 58 years $($ mean $=38.64 ;$ sem $=1.86)$. Most partners were similar in age; the age difference ranged from 0 years to 12 years (mean difference $=2.83$ years; sem $=0.41$ ). Nineteen couples had no children living at home. Seventeen couples had children living at home; 11 of which had at least one child under the age of 10 co-residing. All of the men were in fulltime paid employment, meaning that, for the large part, the actigraphy data included 5 paid employment days and 2 'rest' days. Six of the women described themselves as a 'housewife' or 'not in employment', three were full-time students and the remainder were employed in a wide range of full or part-time jobs. The mean difference in Horne and Östberg score (Horne and Östberg 1976), a measure of diurnal preference, was 7.82 (s.d.=6.42). This suggests that individuals were not selecting partners with similar diurnal patterns.

\section{Actigraphy}

As well as completing the Horne and Östberg questionnaire and the Pittsburgh Sleep Quality Index questionnaire (Buysse et al 1989), each partner wore an actigraph for 1 week.

Actigraphically recorded measurement data can, with high reliability, be translated into information about a person's sleep (Webster et al 1982; Cole et al 1992; Sadeh et al 1994; Sadeh et al 1995; Blood et al 1997). Variables such as 'sleep latency', 'sleep efficiency', 'number of awakenings' and 'sleep fragmentation' are now routinely derived from actigraphy data (Knutson et al 2007).

Within the present study, actiwatches (Cambridge Neurotechnology Ltd, [CNT] Cambridge, UK) were set to collect data at 1 minute epochs. All watches were calibrated using standardized equipment from CNT prior to use. Actigraphy files were downloaded and summarised using inbuilt algorithms within the manufacturer's software 'Sleep Analysis 5' (Cambridge Neurotechnology Ltd).

Following Morgenthaler et al's (2007) recommendation that careful attention be paid to start and stop times, three steps were taken to ensure the accuracy of our analysis: first, as all of 
the sleep variables are calculated in relation to 'bed time' and 'get up time', participants were asked to press an 'event button' (positioned on the surface of the watch) when they were in bed ready to go to sleep and when they awoke in the morning. This event press was recorded within the actigraph's memory. Second, two experienced actigraphy scorers independently analysed the files. Results were then compared, and any discrepancies between the two led to further investigation. Particular attention was paid to those files where the subject did not comply fully with marker press instructions and the person analysing was required to estimate 'bed time' and/or 'get up time' ( $\mathrm{n}=87$ nights out of a total of 473 nights). Third, audio diaries were referred to throughout the analysis and especially in cases where the 'bed time' or 'get up time' were ambiguous. Although Lockley et al (1999) have shown that subjective written diaries and actigraphy are poorly correlated in relation to number and duration of awakenings the audio diaries within this study were differentiated from earlier research, especially because bed partners were able to provide extensive data about each night.

\section{Audio Diaries}

Audio diaries (Sony Dictaphones) were given to each partner with the instruction that, for the following 7 days, they should record, after awakening in the morning, any information they wished about their sleep or wake during the previous night. Written instructions to this effect were provided, which asked them specifically to record bed times, any disturbances throughout the night, and number and times of awakening. Subjects were also instructed that they could make multiple entries and return to the audio diary on as many occasions as they wished throughout the day. The completed audio sleep diary recordings were transcribed in full. A detailed discussion of this method can be found in Hislop et al (2005).

\section{Measures}

Twelve variables were calculated for each bed partner. These variables measure aspects of sleep timing, sleep quality and circadian rhythmicity. The sleep timing variables included 'Preferred bed time' (taken from questionnaire items which asked about the time that partners would like to go to bed), 'Actual bed time' and 'Get up time' (both of which were calculated from marker presses within the actigraphy) and 'Difference between preferred and actual bedtime'. Sleep quality variables were all calculated from the actigraphy data and included 'Sleep latency', 'Actual sleep time', 'Sleep efficiency', 'Wake bouts' (number of times the subject woke during the night), 'Light/Dark ratio' (the difference between amount of daytime 
movement and nighttime movement) and 'Fragmentation index'. As an indication of circadian rhythmicity the 'interdaily stability' and 'intradaily variability' were calculated. The 'interdaily stability' (IS) 'gives an indication of the strength of the coupling between the rest-activity rhythm and Zeitgebers' (Van Someren et al 1997, p. 957). The 'intradaily variability' (IV) 'gives an indication of the fragmentation of the rhythm' (Van Someren et al 1997, p. 957). Both variables were created following the method described in Van Someren et al (1997).

\section{Statistical approaches to examining the interdependence of couple data}

There is debate surrounding how the interdependence of couples' sleep should be measured. Standard correlation analysis techniques are often applied to data on couples (Kenny and Cook 1999), in which sleep data is aggregated to give an average score for each individual within the couple. Each spouses' aggregated score would then be correlated with their partner's aggregated score. With heterosexual dyads these techniques quantify the extent to which women who receive a high score on a variable, relative to other women, are matched with men who receive a high score, relative to other men. However, this aggregation may result in cross-level errors or level of analysis errors (Gonzalez and Griffin 1997) and ignore potentially interesting autocorrelations between nights.

Researchers also disagree over the appropriateness of using Hierarchical Linear Modelling to examine couples' sleep. Some authors suggest that it is a useful method for identifying and handling the interdependence of married/cohabiting couples' data (DeLongis and Holtzman 2005, p. 5-6). While others, such as Laurenceau and Bolger (2005) and Kenny et al (2006), criticise the use of Hierarchical Linear Modelling within research on couples. In their discussion of multilevel models with binary outcomes, McMahon et al (2006) suggest that it is often not feasible to estimate random effects for both the intercept and slope because there are only two observations per cluster (i.e. per couple). Further to this, dyads in which both members have identical responses do not contribute to the likelihood function.

\section{Statistical analysis}

In light of these debates, and the aims of the paper, analysis was undertaken in three stages: First, we began by inspecting the validity of the data. The Kolmogorov-Smirnov (K-S) test was applied to test for normality (using SPSS v14 ${ }^{1}$.) and reliability measures were obtained (using HLM for windows, version 6.02a; Raudenbush and Bryk 2002). Reliability measures 
indicate whether the sample mean is a reliable estimate of the true mean. Reliability scores range from 0 to 1 and reliability is considered medium if greater than 0.5 or large if greater than 0.7. Residuals were also plotted to identify the number of couples which differed significantly from the average at the 5\% level. Outliers were removed from the data set prior to further analysis. As Langford and Lewis (1998) suggest, the word 'outlier' is used by different writers in different senses. Here we use the term to describe a situation where: i) significant difference between couples exists; and ii) this significant difference between couples no longer exists when a single couple is removed from the model.

Second, we examined the shared variance between partners within couples using unconditional hierarchical linear models (Raudenbush and Bryk 2002). For each dependent variable, intraclass correlations (ICC) were calculated to give an indication of the proportion of the total variation that is accounted for by higher level units. For the two level models (which analyse IS, IV, 'Preferred bedtime') we calculated the proportion of the total variance which occurs between individuals (Level 1) and between couples (Level 2). For the three level models (which include 'Sleep efficiency', 'Wake bouts', 'Fragmentation index' and 'Actual bed time') we calculated the portion of the total variation which occurs between nights (Level 1), between individuals (Level 2) and between couples (Level 3) (cf. Singer 1998).

Because the ICC indicates proportion of variance at the couple level, it can be high even when the actual amount of variation is small. Therefore, tests were performed to calculate whether the proportion of the variation at the couple level is statistically significant. Each model was run in MLwiN (version 2.02; Rasbash et al 2005) with and without the couple level. The likelihood ratio statistic was then obtained by subtracting the $-2 * \log$ likelihoods of the two models and comparing the result to a chi-squared distribution on 1 degree of freedom (Rasbash et al 2005).

Finally, we investigated how much of the variance component at the couple level truly results from couple dynamics. Couples in this study tended to be of similar age and, as age can affect sleep and rhythms, some of the couple ICC could be due to similar ages of partners and not specifically related to dyadic interdependence, shared events or direct impacts ${ }^{2}$. Huang et al (2002), for example, suggest that the IV of those aged $61-91$ is significantly higher than those aged 21-44 and Monk et al (2006) found that compared to younger adults older 
adults have a highly regular lifestyle. Therefore, 'age' was added to the models and changes in the proportion of variance at the couple level noted. 'Presence of children' was also added and changes in couple level variance observed. Due to differing rates of compliance among the sleep measures used, the total number of participants within the models discussed below varies.

\section{Results}

Data was checked for validity. 'Get up time', 'Sleep efficiency' and 'Difference between preferred and actual bed time' were not normally distributed. This was not resolved by log transformation and no further analysis was performed on these three variables.

Figure 1 shows the number of couples which differ significantly from the average for the remaining nine sleep variables. As Figure 1 illustrates, with interdaily stability (IS) only one couple differed significantly from the average at the 5\% level. Similarly, with intradaily variability (IV) only 1 couple were significantly different from the average at the 5\% level. When these two couples were removed from the analysis there were no significant differences between couples and a large proportion of the couple level variation was removed. Therefore these two couples were considered outliers and removed from further analysis of interdaily stability and intradaily variability.

\section{Insert Figure 1 about here}

Figure 1 also suggests that there is little couple level variation for 'Actual sleep time' and 'Fragmentation index' (as $d=0$ ). The residual plots in Figure 1 do indicate the existence of some couple level variation in 'Preferred bed time' $(\mathrm{d}=3)$, 'Sleep latency' $(\mathrm{d}=4)$, 'Light/Dark ratio' $(d=4)$, and a high degree of couple level variation in 'Wake bouts' $(d=8)$ and 'Actual bed time' $(\mathrm{d}=17)$. This was confirmed by the unconditional models: 'Preferred bed time' (couple level ICC $=0.42 ; \mathrm{p}<0.01$ ), 'Sleep latency' (couple level ICC $=0.25, \mathrm{p}<0.001$ ), 'Light/Dark ratio' (couple level ICC=0.28, $\mathrm{p}<0.001$ ), 'Wake bouts' (couple level ICC $=0.42$, $\mathrm{p}<0.001$ ) and 'Actual bed time' (couple level $\mathrm{ICC}=0.52, \mathrm{p}<0.001$ ) all showed significant clustering at the couple level. 
However, as Table 1 illustrates, after including 'age' and 'presence of children' in the models, only 'Sleep latency', 'Light/Dark ratio', 'Wake bouts' and 'Actual bed time', remained showing significant variance at the couple level ${ }^{3}$. Further to this, the proportion of variance at the couple level for 'Sleep latency' reduced from 0.25 to 0.18 .

\section{Insert Table 1 about here}

\section{Discussion}

This paper has examined actigraphic data collected from 36 couples for one week. It has investigated the partitioning of variance in twelve sleep/wake variables: 'Preferred bed time', 'Actual bed time', 'Get up time', 'Difference between preferred and actual bed time', 'Actual sleep time; 'Light/Dark ratio', 'Sleep latency', 'Sleep efficiency', 'Fragmentation index', 'Number of wake bouts', 'Intradaily variability' and 'Interdaily stability'. 'Get up time', 'Sleep efficiency' and 'Difference between preferred and actual bed time' were not normally distributed and no further analysis was performed on these variables.

After adding covariates to the models, four of the nine remaining variables showed significant clustering at the couple level: 'Actual bed time', 'Sleep latency', 'Light/Dark ratio' and 'Wake bouts'. These findings extend those of previous studies. Crossley (2004, p. 18) suggests that 'In situations of co-presence the parties to that situation need to secure cooperation from one another for their own sleep ritual, whether this means common bedtimes and sleep conditions or different but complementary patterns, with each party respecting the needs of the other.' Within the present study a large proportion of the variance for 'actual bed time' resided at the couple level; suggesting a couple dynamic in the timing of bed. Yet, for 'Preferred bed time' the largest proportion of the variance was at the individual level, suggesting that couples do not necessarily want to go to their shared bed at the same time.

The results for 'Wake bouts' confirm earlier research which suggests that about one third of nocturnal awakenings are similar to bed partners. In two related studies, Pankhurst and Horne (1994) examined actigraphically recorded concordance in movement in 46 pairs of bed partners and the differences in nocturnal movement in those with and without bed partners. The authors concluded that approximately one-third of measured movements were common to both bed-partners, although couples did not seem aware of this concordance and reported sleeping better when their partner was there. 
Where this study differs is that it quantifies those variables which are susceptible to dyadic influence, illustrating the strength of the clustering whilst isolating the potential effects of potential cofounders, such as age. It illustrates how social factors impinge on the timing (and quality) of sleep-wake cycles and that bed partners are an important part of these social factors. Our findings exemplify how the dyadic nature of couples' sleep needs to be given much more attention. As Troxel et al (2007, p. 389) suggest, 'recognizing the dyadic nature of sleep and incorporating such knowledge into both clinical practice and research in sleep medicine may elucidate key mechanisms in the etiology and maintenance of both sleep disorders and relationship problems and may ultimately inform novel treatments'. Indeed, a small scale study by Cartwright (2008) found that continuous positive airway pressure (CPAP) compliance in married men is (positively) related to the frequency with which his partner sleeps with him. Interdependence between partners within couples is not simply a statistical nuisance or a logistical problem. Interdependence may be the defining feature of relationships (Kenny and Cook 1999) and, in societies where it is common for adult partners to share a bed (Hislop 2007), it is perhaps also the defining feature of sleep.

\section{Notes}

1 - Three different software packages were used for the analysis (SPSS, HLM and MLwiN). HLM was used for the reliability measures, K-S test results were obtained from SPSS v14 and the variance component information was taken from MLwiN. No single package could offer all the information required. For example, HLM is one of the few packages which provides reliability measures, yet the p-values and confidence intervals produced by HLM differ from those obtained by most other programs (Hox 2002, p. 42).

2- We are grateful to one of the reviewers who pointed out the importance of addressing this point.

3- MCMC analysis confirmed the substantial interdependence in bed partner's actual bed time, sleep latency, light/dark ratio and wake bouts. MCMC is a conservative estimation method in Hierarchical Linear Modelling. 


\section{Acknowledgements}

The authors would like to offer sincere thanks to Vicky Vaughan for assisting with the data collection and Ian Brunton-Smith and the reviewers for useful pointers and probing questions. This study was funded by Economic and Social Research Council grant RES-00023-0268. 


\section{References}

Adams BN, Cromwell RE. (1978). Morning and night people in the family: a preliminary statement. Fam. Coord. 27:5-13

Beninati W, Harris CD, Herold DL, Shepard JW, Jr. (1999). The effect of snoring and obstructive sleep apnea on the sleep quality of bed partners. Mayo. Clin. Proc. 74:955-958 Blood ML, Sack RL, Percy DC, Pen JC. (1997). A comparison of sleep detection by wrist actigraphy, behavioural response, and polysomnography. Sleep 6:388-395

Cartwright R. (2008). Sleeping together: a pilot study of the effects of shared sleeping on adherence to CPAP treatment in obstructive sleep apnea. JCSM 4:123-127

Cartwright, RD, Knight, S. (1987). Silent partners: the wives of sleep apneic patients. Sleep $10: 244-8$

Buysse DJ, Reynolds CF, Monk TH, Buman SR, Kupfer DJ. (1989). Pittsburgh Sleep Quality Index: a new instrument for psychiatric practice and research. Psychiat. Res. 28:193-213 Cole RJ, Kripke DF, Gruen W, Mullany DJ, Gillin JC. (1992). Automatic sleep/wake identification from wrist activity. Sleep 15:461-9

Crossley N. (2004). Sleep, reflexive embodiment and social networks, Paper presented at the first ESRC 'Sleep and Society' seminar, 3 December, University of Warwick

Delongis A, Holtzman S. (2005). Coping in context: the role of stress, social support, and personality in coping. J. Pers. 73:1633-1656

Dittami J, Keckeis M, Machatschke I, Katina S, Zeitlhofer J, Kloesch G. (2007). Sex differences in the reactions to sleeping in pairs versus sleeping alone in humans. Sleep Biol. Rhythms 5:271-276

Gonzalez R, Griffin D. (1997). The statistics of interdependence: treating dyadic data with respect. In SW, Duck (Ed.), Handbook of Personal Relationships: Theory, Research, and Interventions (2nd $\mathrm{Ed})$. Chichester: Wiley

Huang Y-L, Liu R-Y, Wang Q-S, Van Someren EJW, Xu H, Zhou J-N. (2002). Ageassociated difference in circadian sleep-wake and rest-activity rhythms. Physiol. Behav. 76:597-603

Hislop J. (2007). A bed of roses or a bed of thorns? Negotiating the couple relationship through sleep. Sociol. Res. Online 12: http://www.socresonline.org.uk/12/5/2.html Hislop J, Arber S, Meadows R, Venn S. (2005). Narratives of the night: the use of audio diaries in researching sleep. Sociol. Res. Online 10: http://www.socresonline.org.uk/10/4/hislop.html 
Horne JA, Östberg O. (1976). A self-assessment questionnaire to determine morningeveningness in human circadian rhythms. Int. J. Chronobiol. 4:97-110

Hox, J. (2002). Multilevel analysis: techniques and applications. Lawrence Erlbaum Associates

Kenny DA, Cook W. (1999). Partner effects in relationship research: conceptual issues, analytic difficulties, and illustrations. Pers. Relationship. 6:433-448.

Kenny DA, Kashy DA, Cook WL. (2006). Dyadic data analysis. London: Guilford Press Knutson KL, Rathouz PJ, Lijing LY, Liu K, Lauderdale DS. (2007). Intra-individual daily and yearly variability in actigraphically recorded sleep measures: the CARDIA Study. Sleep 30: 793-796

Kushida CA. (2004). Sleep deprivation: clinical issues, pharmacology and sleep loss effects. Informa Health Care

Langford IH, Lewis T. (1998). Outliers in multilevel data. J. Roy. Statistical Society 161:121160

Larson JH, Crane DR, Smith CW. (1991). Morning and night couples: the effect of wake and sleep patterns on marital adjustment. J Marital Fam. Ther. 17:53-65.

Laurenceau J-P, Bolger N. (2005). Using diary methods to study marital and family processes. J. Fam. Psychol. 19:86-97.

Lockley SW, Skene DJ, Arendt J. (1999). Comparison between subjective and actigraphic measurement of sleep and sleep rhythms. J. Sleep Res. 8:175-183

McMahon JR, Pouget ER, Tortu S. (2006). A guide for multilevel modelling of dyadic data with binary outcomes using SAS PROC MIXED. Comput. Stat. Data An.

Monk TH, Buysse DJ, Hall M, Nofzinger EA, Thompson WK, Mazumdar SA, Reynolds III CF. (2006). Age-related differences in the lifestyle regularity of seniors experiencing bereavement, care-giving, insomnia, and advancement into old-old age. Chronobiol. Int. 23:831-841

Monroe LJ. (1969). Transient changes in EEG sleep patterns of married good sleepers: the effects of altering sleeping arrangement. Psychophysiology 6:330-7

Morgenthaler T, Aless C, Friedman L, Owens J, Kapur V, Boehlecke B, Brown T, Chesson A, Coleman J, Lee-Chiong T, Pancer J, Swick TJ. (2007). Practice parameters for the use of actigraphy in the assessment of sleep and sleep disorders: An update for 2007. Sleep 30:519529

Pankhurst FP, Horne JA. (1994). The influence of bed partners on movement during sleep. Sleep 17:308-315 
Parish JM, Lyng PJ, (2003). Quality of life in bed partners of patients with obstructive sleep apnea or hypopnea after treatment with continuous positive airway pressure. Chest 124:942947

Rasbash J, Steele F, Browne WJ, Prosser B. (2005). A users guide to MLwiN version 2.0. University of Bristol

Raudenbush SW, Bryk AS. (2002). Hierarchical linear models: applications and data analysis methods. ( $2^{\text {nd }}$ ed). CA: Sage

Rosenblatt PC. (2006). Two in a bed: the social system of couple bed sharing. New York, State University of New York Press

Sadeh A, Acebo C, Seifer R, Aytur S, Carskadon MA. (1995). Activity-based assessment of sleep-wake patterns during the $1^{\text {st }}$ year of life. Infant Behav. Dev. 18:329-337

Sadeh A, Sharkey KM, Carskadon MA. (1994). Activity based sleep-wake identification: an empirical test of methodological issues. Sleep 17:201-207

Singer JD. (1998). Using SAS PROC MIXED to fit multilevel models, hierarchical models and linear growth models. J Educ. Behav. Stat. 24:323-355

Strawbridge WJ, Shema SJ, Roberts RE. (2004). Impact of spouses sleep problems on partners. Sleep 27:527-531

Troxel WM, Robles TF, Hall M, Buysse DJ. (2007). Marital quality and the marital bed: examining the covariation between relationship quality and sleep. Sleep Med. Rev. 11:389404

Touitou Y, Smolensky MH, Portaluppi F. (2006). Ethics, standards and procedures in human and animal research in chronobiology. Chronobiol. Int. 23:1083-1096.

Ulfberg J, Carter N, Talback M, Edling C. (2000). Adverse health effects among women living with heavy snorers. Health Care Women Int. 21:81-90

Van Someren EJW, Kessler A, Mirmiran M, Swaab DF. (1997). Indirect bright light improves circadian rest-activity rhythm disturbances in demented patients. Biol. Psychiat. 4:955-963

Venn S. (2007). 'It's ok for a man to snore.' The influence of gender in addressing sleep disruption in couples. Sociol. Res. Online 12 http://www.socresonline.org.uk/12/5/1.html Webster JB, Kripke DF, Messi S, Mullany DJ, Wyborney G. (1982). An activity-based sleep monitor system for ambulatory use. Sleep 5:389-99 
Table 1: Hierarchical Linear Model Results for 36 couples (72 subjects) over one week after removing outliers and including 'age' and 'presence of children' as predictors.

\begin{tabular}{|c|c|c|c|c|c|c|c|c|c|c|}
\hline & & $\begin{array}{l}\text { Interdaily } \\
\text { Stability }\end{array}$ & $\begin{array}{l}\text { Intradaily } \\
\text { variability }\end{array}$ & $\begin{array}{l}\text { Preferred } \\
\text { Bed Time }\end{array}$ & $\begin{array}{l}\text { Actual } \\
\text { bed Time }\end{array}$ & $\begin{array}{l}\text { Actual } \\
\text { Sleep } \\
\text { Time }\end{array}$ & $\begin{array}{l}\text { Sleep } \\
\text { Latency }\end{array}$ & $\begin{array}{l}\text { Light/ } \\
\text { Dark } \\
\text { Ratio }\end{array}$ & $\begin{array}{l}\text { Fragmentation } \\
\text { Index }\end{array}$ & $\begin{array}{l}\text { Wake } \\
\text { Bouts }\end{array}$ \\
\hline \multirow[t]{5}{*}{ Descriptive } & $\mathbf{N}$ & 66 & 66 & 64 & 350 & 350 & 350 & 292 & 350 & 350 \\
\hline & Mean & 0.61 & 0.73 & 1395.08 & 1404.99 & 395.89 & 19.41 & 3.32 & 30.69 & 28.85 \\
\hline & SD & 0.11 & 0.18 & 51.69 & 59.97 & 59.58 & 15.24 & 3.33 & 12.83 & 10.40 \\
\hline & Min & 0.35 & 0.32 & 1290 & 1203.00 & 218 & 0 & 0.7 & 4.30 & 5 \\
\hline & Max & 0.82 & 1.16 & 1560 & 1693.00 & 565 & 109.82 & 37.7 & 71.20 & 65 \\
\hline \multirow{3}{*}{$\begin{array}{l}\text { Variance } \\
\text { [ICC] }\end{array}$} & Night & - & - & - & 1745.28 & 1685.23 & 159.10 & 0.04 & 62.91 & 30.58 \\
\hline & Subject & 0.010 & 0.026 & 1659.85 & $\begin{array}{l}20.12 \\
{[\mathbf{0 . 0 1}]}\end{array}$ & $\begin{array}{l}1322.08 \\
{[\mathbf{0 . 3 8}]}\end{array}$ & $\begin{array}{l}13.86 \\
{[0.07]}\end{array}$ & $\begin{array}{l}0.005 \\
{[\mathbf{0 . 0 8}]}\end{array}$ & $\begin{array}{l}76.12 \\
{[0.47]}\end{array}$ & $\begin{array}{l}31.22 \\
{[0.29]}\end{array}$ \\
\hline & Couple & $\begin{array}{l}0 \\
{[0]}\end{array}$ & $\begin{array}{l}0.004 \\
{[\mathbf{0 . 1 3}]}\end{array}$ & $\begin{array}{l}538.16 \\
{[0.24]}\end{array}$ & $\begin{array}{l}1790.28 \\
{[\mathbf{0 . 5 0 ]}} \\
* * *\end{array}$ & $\begin{array}{l}508.79 \\
{[\mathbf{0 . 1 4}]}\end{array}$ & $\begin{array}{l}37.34 \\
{[0.18]} \\
* *\end{array}$ & $\begin{array}{l}0.016 \\
{[0.26]} \\
* * * *\end{array}$ & $\begin{array}{l}24.68 \\
{[0.15]}\end{array}$ & $\begin{array}{l}4.05 \\
{[\mathbf{0 . 4 2}]} \\
* * * *\end{array}$ \\
\hline \multirow[t]{2}{*}{ Reliability } & Level 2 & - & - & & 0.031 & 0.79 & 0.35 & 0.397 & 0.853 & 0.832 \\
\hline & Level 3 & 0.302 & 0.368 & 0.596 & 0.911 & 0.4 & 0.7 & 0.683 & 0.368 & 0.708 \\
\hline $\begin{array}{l}\text { Kolmogorov- } \\
\text { Smirnov }\end{array}$ & & $\begin{array}{l}0.421 \\
(\mathrm{p}=0.994)\end{array}$ & $\begin{array}{l}0.701 \\
(\mathrm{p}=0.710)\end{array}$ & $\begin{array}{l}1.106 \\
(\mathrm{p}=0.173)\end{array}$ & $\begin{array}{l}1.049 \\
(\mathrm{p}=0.221)\end{array}$ & $\begin{array}{l}0.918 \\
(\mathrm{p}=0.369)\end{array}$ & $\begin{array}{l}1.135 \\
(\mathrm{p}=0.152)\end{array}$ & $\begin{array}{l}1.139 \\
(\mathrm{p}=0.149)\end{array}$ & $\begin{array}{l}0.434 \\
(\mathrm{p}=0.992)\end{array}$ & $\begin{array}{l}0.757 \\
(p=0.615)\end{array}$ \\
\hline
\end{tabular}

This table illustrates the results from the Unconditional Hierarchical Linear Models. The descriptives include the number of individuals (or nights for three level data) in the data set (N) and the mean, standard deviation (SD), min and max for each variable. The variance columns provide the actual variance and the proportion of variance [ICC] at each level. Actual Bed Time, actual sleep time, sleep latency,

fragmentation index, Light/Dark ratio and wake bouts all include weekdays only. Sleep Latency and Light/Dark ratio were log transformed.

$*$ indicates significant differences between couples. ${ }^{*} \mathrm{p}<0.5, * * \mathrm{p}<0.01, * * * \mathrm{p}<0.001$ 
Figure 1 - Caterpillar plots for nine variables, showing each couple and whether they differ significantly from the average at the $5 \%$ level.

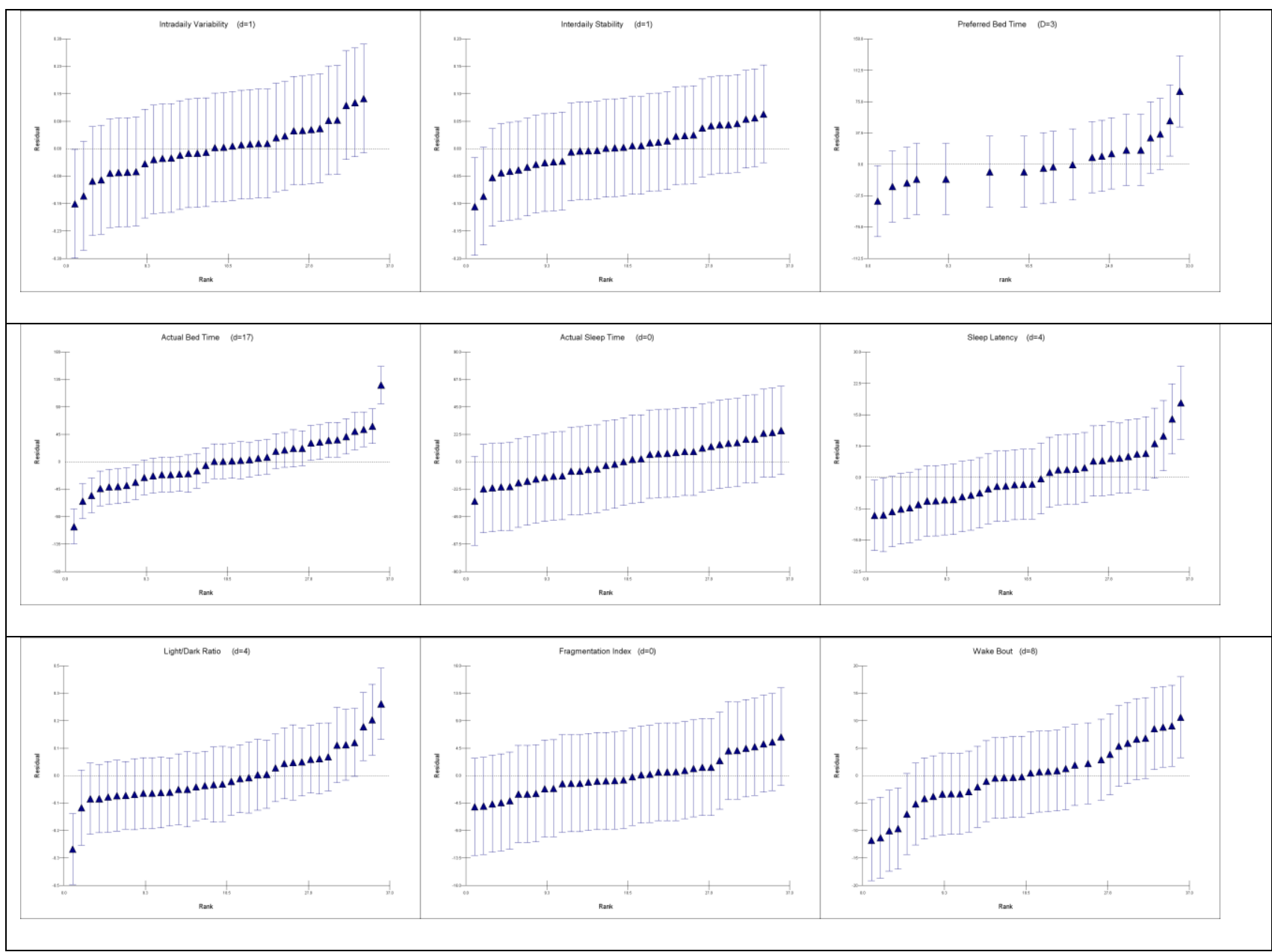

The figures above plot the Couple Level residual (+/- $1.96 \mathrm{sd})$ against the 'rank'. These figures are useful as they enable the identification of the number of couples which differ significantly from the average at the $5 \%$ level (indicated on each graph by $\mathrm{d}=\mathrm{x}$ ). Where the error bars do not cross 0 couples can be considered significantly different. Those above the 0 line have a significantly higher outcome on the

dependent variable and those below the 0 line have a significantly lower outcome on the dependent variable. There are fewer couples in the 'preferred bed time' graph, as residual plots do not include couples where the bed partners had exactly the same preferred bed time. That is, because of the similarities in bed times across the data set as a whole, some couples are ranked exactly the same as other couples. 